\title{
Reconfigurable Filtenna using Varactor Diode for Wireless Applications
}

\author{
J. A. I. Araujo ${ }^{1}$, M. R. T. Oliveira ${ }^{2}$ (D) P. H. B. Cavalcanti Filho ${ }^{1}$ (D) C. P. N. Silva ${ }^{1}$, \\ M. S. Coutinho ${ }^{1}$ (D) M. T. de Melo ${ }^{1}$ (D) Ignacio Llamas-Garro $^{3}$ (D), A. G. Barboza ${ }^{1}$ (D) \\ ${ }^{I}$ Departamento de Eletronica e Sistemas, Universidade Federal de Pernambuco, Recife, Brazil, \\ jorgeantonio1@me.com,pedrobcv@gmail.com,crislanepns@gmail.com,marcostdemelo@gmail.com, \\ amanda_bgomees@hotmail.com \\ ${ }^{2}$ Instituto Federal de Pernambuco, Garanhuns, Brazil, \\ manuregina10@gmail.com, \\ ${ }^{3}$ Centre Tecnologic de Telecomunicacions de Catalunya (CTTC/CERCA), 08860 Castelldefels, Spain, \\ ignacio.llamas@cttc.es
}

\begin{abstract}
This paper presents a compact and planar reconfigurable filtenna for application in Wireless systems. The filtenna is composed of a UWB circular antenna and a filter with two trapezoidal resonators. The filter is integrated on the antenna feed line and has a band-pass frequency response. The filtenna frequency response reconfiguration is achieved by changing the capacitance of a varactor diode, placed between filter resonators; the capacitance varies continuously from $1.32 \mathrm{pF}$ to $4.09 \mathrm{pF}$ according to an applied bias voltage. The varactor capacitance analog variation defines the filtenna frequency of operation, which can be varied from $2.2 \mathrm{GHz}$ to $3.4 \mathrm{GHz}$ with an average bandwidth of $200 \mathrm{MHz}$, while maintaining the radiation characteristics of the UWB antenna. Simulated and measured filtenna results are shown according to varactor diode bias, demonstrating multiband operation using a compact planar design.
\end{abstract}

Index Terms - Antenna, Filtenna, Reconfigurable filter, Varactor Diode, Wireless communication.

\section{INTRODUCTION}

Wireless communication systems are increasingly present in the day-to-day of human society due to the increased development of versatile devices with the most varied types of applications [1]-[2]. Some of these devices, such as mobile phones and GPS, can operate on a variety of wireless communication protocols such as WiFi, WiMAX, WLAN, Bluetooth, GSM, and others [3].

Current wireless systems require low cost, compact and lightweight features suitable for user portability. The development of antennas capable of working optimally, ensuring the versatility of these systems such as multiband operation, is an important requirement to meet the current needs of wireless communication systems [4].

Antennas and filters are usually the largest elements in wireless communication systems, there is interest in creating a single module that integrates these components, while maintaining the filtering and radiation characteristics of each element [5].

The first references found in the literature about filtennas date back to 2002. These works already integrated filters and antennas in a single module [6]-[11]. In [6], the module consisted of a direct connection between independent antenna and filter that met the proposed design objectives, however 
Journal of Microwaves, Optoelectronics and Electromagnetic Applications, Vol. 20, No. 4, December 2021

DOI: http://dx.doi.org/10.1590/2179-10742021v20i41152

the module did not provide predictable results, as the filter response worsened due to module impedance mismatch, resulting from element connection. With the objective of making the impedance mismatch losses smaller, the antenna-filter integration approach also results in size reduction [7]-[8]. However, the systems did not present overall good performance related to selectivity parameters and band-rejection characteristics. The miniaturization of communication system front end was possible due to the integration of filters directly on the antenna feedlines, with versatility ensured, due to the inherent possibility of reconfiguration of these systems. In [9] and [10] a band-pass filter is integrated into the feedline of an ultra-wideband (UWB) patch antenna, the reconfiguration was made using selective keys modeled as copper tapes which generated system operation modes: broadband mode and narrow-band mode. The inconvenience was the difficulty to perform the reconfiguration, because it was necessary to short-circuit parts of the structure to switch between the modes of operation. The work in [11] uses a similar approach, but this time the reconfiguration is done using PIN diodes. Through diode states (ON and OFF) the design presented a broadband operation, where the frequency of $5.25 \mathrm{GHz}$ or $5.8 \mathrm{GHz}$ can be rejected according to PIN diode bias. This integration presented good results, with attenuation of about $30 \mathrm{~dB}$.

In this letter, a new type of planar reconfigurable and compact filtenna for multiband wireless communication systems is presented. Through theoretical and computational modelling, a trapezoidal filter, reconfigured by a varactor diode is added to the feedline of a planar monopole UWB antenna. The design is implemented to provide a continuous tunable operating frequency of the antenna in a simple way, without altering its dimensions and radiation pattern. The reconfiguration of the filter is performed through a varactor diode, whose capacitance is varied depending on the reverse voltage applied, the frequency tuning is in the range from $2.2 \mathrm{GHz}$ to $3.4 \mathrm{GHz}$.

\section{THEORETICAL BACKGROUND}

Planar filtennas perform the combined task of planar filters and antennas, with the advantages being easy to manufacture and good radiation properties using an integrated and compact design. The planar filtenna is composed of a planar antenna with a planar filter embedded in its feed line [12].

\section{A. UWB planar monopole antenna}

UWB communication systems consist of a digital data transmission standard, with a wide frequency range of operation and low power consumption. This allows high data transmission rates using low power systems [13]. UWB technology is useful for military, commercial, medical, radar and mobile communications applications [14].

UWB is defined as any radio transmission system that has a bandwidth greater than $20 \%$ of its center frequency [15]. These systems transmit a pulse sequence (on the order of picoseconds) over a wide frequency spectrum [13].

Several examples of UWB antennas have been reported in recent years, including frequency 
Journal of Microwaves, Optoelectronics and Electromagnetic Applications, Vol. 20, No. 4, December 2021

DOI: http://dx.doi.org/10.1590/2179-10742021v20i41152

independent antennas, multi-resonant antennas and smart antennas [16]. However, planar antennas are attractive due to their low cost, ease of design and fabrication. Planar monopole antennas exhibit high bandwidth and high radiation efficiency and present different geometries, e.g. triangular, circular, square, trapezoidal, elliptical, and others [17].

The monopole antenna has a UWB characteristic due to the overlap of its resonance modes. The monopole radiation pattern in the E-plane (vertical) is influenced by the higher order modes. In the fundamental mode a stationary wave is formed, because the wavelength of the transmit signal is greater than the physical dimensions of the antenna that operates in an oscillating mode. As the frequency of operation increases, the antenna starts operating in a hybrid mode of stationary waves. Distortions of the radiation pattern occur due to the distribution of the surface current in the higher order modes. Thus, the monopole antenna exhibits broadband characteristics [18]-[20].

In this work, a monopole antenna of circular geometry is chosen, since its linear polarization characteristic is adequate for this project. The monopole antenna is shown in Fig. 1.

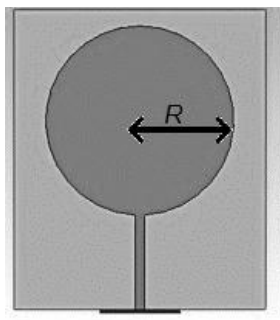

(a)

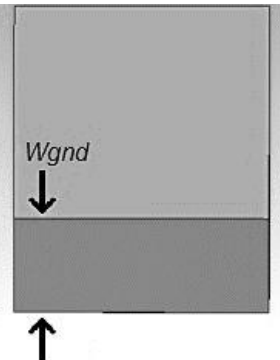

(b)

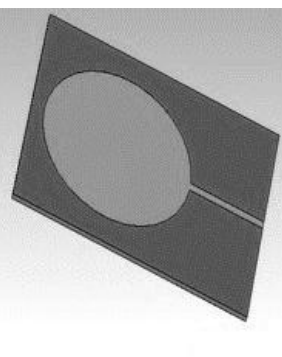

(c)

Fig. 1. UWB planar monopole antenna layout: (a) Front view; (b) Back view; (c) 3D view.

The antenna frequency response is determined by design parameters, with main parameters being the radius $R$ and the width of the ground plane $W_{g n d}$. The radius $R$ establishes the fundamental mode of operation of the antenna and thus the value of the lowest frequency of operation. It can be calculated using the mathematical equation in [21]-[22]. The width of the ground plane $W_{\text {gnd }}$ determines the highest frequency of operation [23].

\section{B. Reconfigurable trapezoidal filter}

In the literature, filters are commonly defined as two-port devices, with one input and one output, used to perform frequency selection or rejection, with an output signal defined by a range of frequencies. Filters are classified according to their frequency response as: low-pass, high-pass, bandpass and band-stop [24].

Preferably, a filter should have a flat pass-band for an entire frequency band of desired operation. It should also present wide attenuation of the unwanted frequency band, frequently requiring an abrupt band-pass to band-stop transition [24]. 
Journal of Microwaves, Optoelectronics and Electromagnetic Applications, Vol. 20, No. 4, December 2021

DOI: http://dx.doi.org/10.1590/2179-10742021v20i41152

In this topic, the filter was modeled and its design steps are detailed. The filter proposed here is an idea derived from [25] that consists of two trapezoidal resonators that have their operating frequency altered by a varactor diode present in the gap between the resonators as in Fig. 2.

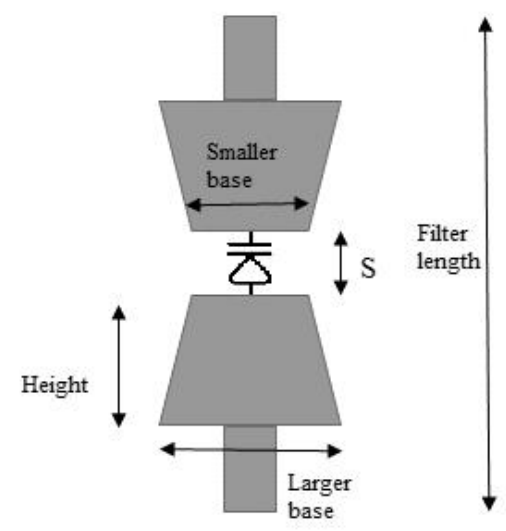

Fig. 2. Resonator with trapezoidal geometry.

Trapezoidal geometry was chosen due to the good resonant frequency reconfiguration sensitivity when the varactor diode present between the resonators has its capacitance changed due to the application of a reverse voltage $\left(V_{R}\right)$. The idea is that the filter is placed in the feed line of the planar monopole antenna previously presented.

The circuit is modeled using capacitances and inductances in an equivalent circuit. Each resonator is modeled as an inductance and in this configuration, these inductances are in series, so the equivalent inductance is given by the summation of these inductances and is represented by $L$ [25]. The value of $L$ in the equivalent circuit is relate to the height, smaller base, and larger base $\left(L_{b}\right)$ dimensions of the trapezoidal resonator from the full-wave simulation.

The resonators also present a gap between them, represented by $S$, and is modeled through capacitances $C_{p}$ and $C_{g}$ as seen in Fig. 3. The capacitance $C_{\mathrm{p}}$ corresponds to the capacitance resulting from the interaction of the feed line with the ground plane while the capacitance $C_{g}$ is the result of the interaction between the coplanar lines. These capacitances can be obtained using the modeling method as presented in [26]-[28].

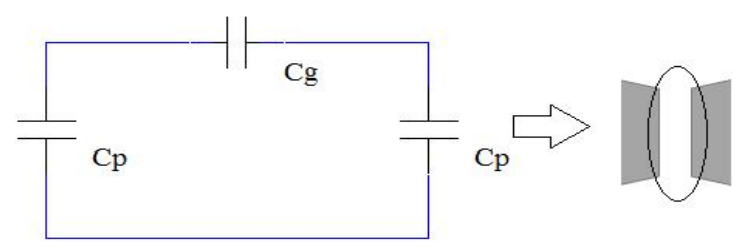

Fig. 3. Equivalent circuit for gap between microstrip lines. 
Journal of Microwaves, Optoelectronics and Electromagnetic Applications, Vol. 20, No. 4, December 2021

DOI: http://dx.doi.org/10.1590/2179-10742021v20i41152

In the gap between the resonators there is also the varactor diode, which is represented by the capacitance $C_{T}$. This capacitance is in series with the equivalent inductance of the resonators $L$ and in parallel with the capacitance $C_{g}$. Finally, having all the representations of the circuit presented, in Fig. 4 it is possible to see the equivalent circuit of the proposed resonator.

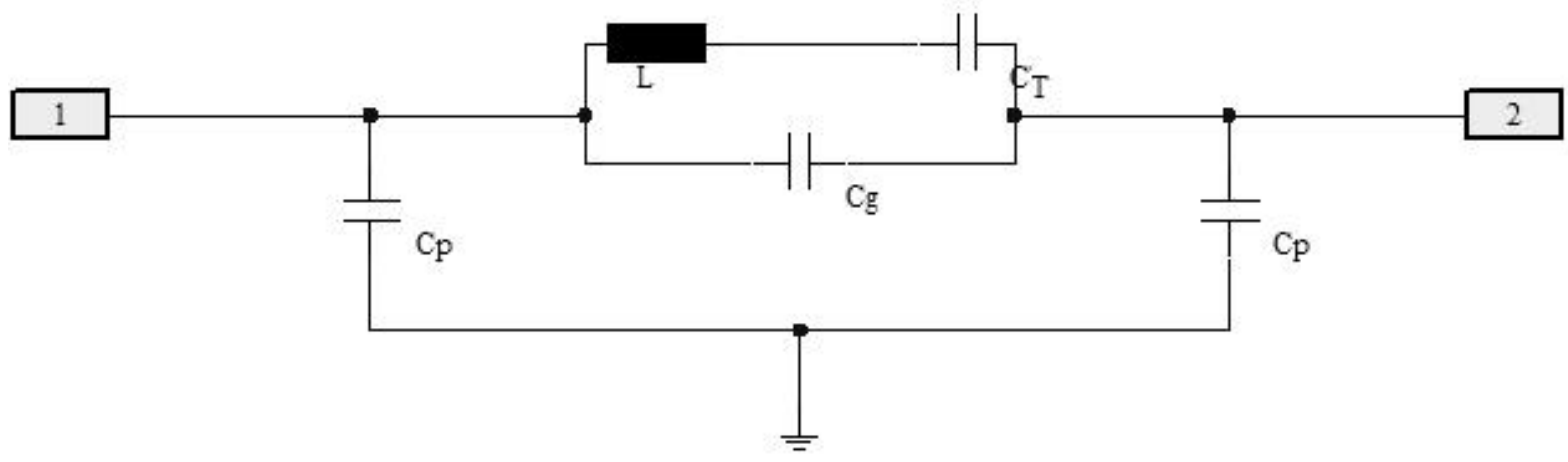

Fig. 4. Equivalent circuit for the trapezoidal filter.

Based on its equivalent circuit, the physical dimensions of the band-pass filter were determined for operating at an initial frequency of $2.5 \mathrm{GHz}$ with a bandwidth approximately $300 \mathrm{MHz}$.

Considering that the maximum length of the filter must be the same length as the feed line of the monopole antenna, which is $30 \mathrm{~mm}$, some dimensions are already predetermined. The trapezoidal resonator height was $6.25 \mathrm{~mm}$ and $S$ is equal to $1 \mathrm{~mm}$. $W$ corresponds to the smaller base of the trapezoid and was considered the same as [25] and is $2.2 \mathrm{~mm}$. The chosen substrate was the FR-4 with $\varepsilon r$ of 4.3 and thickness of $1.6 \mathrm{~mm}$. With these values, it is possible to determine the approximate value of $C_{p}=3.06 \mathrm{pF}$ and $C_{g}=0.03 \mathrm{pF}$.

The $C_{T}$ capacitance value is the capacitance of the chosen varactor diode. For the modeling, a capacitance of $4.09 \mathrm{pF}$ was chosen.

With the predetermined $C_{p}, C_{g}$ and $C_{t}$ values, the optimization of CST Studio Suite ${ }^{\circledR}$ software was used to determine the value of the trapezoid largest base $\left(\mathrm{L}_{b}\right)$ width for a desired resonant frequency of $2.5 \mathrm{GHz}$. The Fig. 5. shows a flowchart of the procedure.

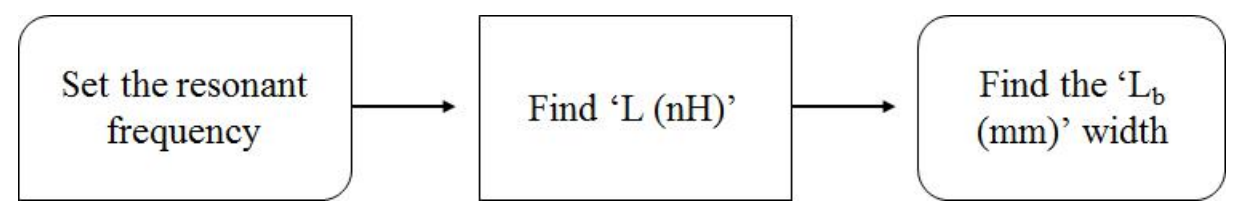

Fig. 5. Flowchart of an optimized simulation proceeding to obtain the $\mathrm{L}_{\mathrm{b}}$ length.

A relation between $L$ and the resonant frequency was made via optimization by CST Studio Suite ${ }^{\circledR}$ and is shown in Fig. 6. A linear fit was also calculated to determine a function that represents this relation. The best fits the data points is a straight line. 


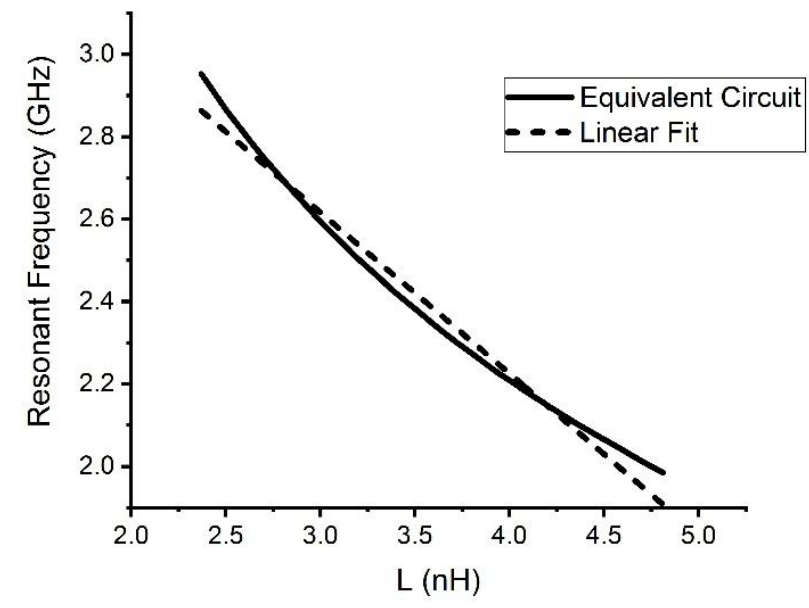

Fig. 6. Relation between L and Resonant frequency for equivalent filter circuit.

The function that represents Fig. 6 relation is approximately given by $f(L)=$ $3.79096-0.40094 \mathrm{~L}$. For a resonant frequency of $2.5 \mathrm{GHz}$ the $L$ is equal to $3.21983 \mathrm{nH}$. With the $L$ value found it is possible to determine the value for the $L_{b}$ length by linear fit equation of the optimized simulation in Fig. 7.

The value of $L$ of the equivalent circuit allows finding, for a given value of the smaller base and the height of the resonator, the value of the larger base $\left(L_{b}\right)$ used in the model in Fig. 2.

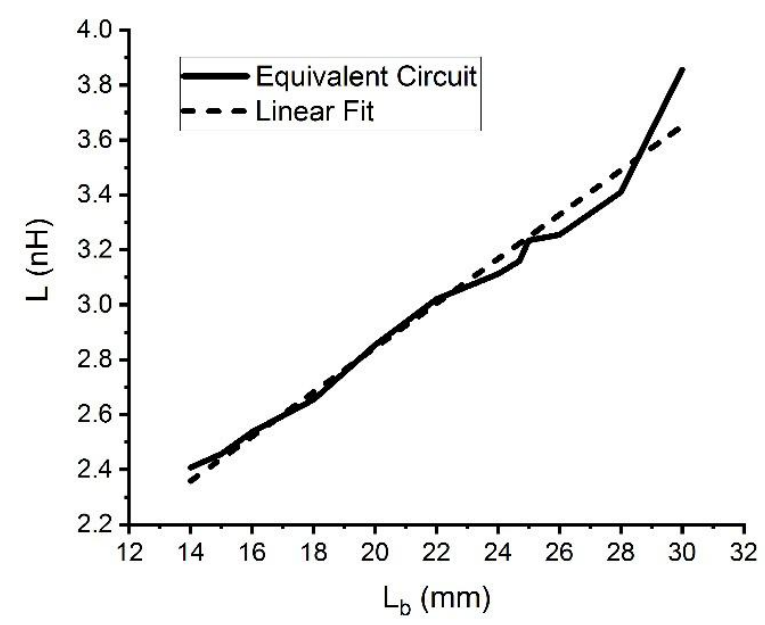

Fig. 7. Relation between $L$ and $L_{b}$ for equivalent filter circuit.

The function that represents this relation is approximately, $L\left(L_{b}\right)=1.22713+0.08068 L_{b}$. For $L$ equals to $3.21983 \mathrm{nH}$ the $L_{b}$ of the filter is approximately $24.7 \mathrm{~mm}$. With these results, it was possible to determine the dimensions of the trapezoidal filter to contemplate the design specifications. The values used in the project are shown in Table I. 
Journal of Microwaves, Optoelectronics and Electromagnetic Applications, Vol. 20, No. 4, December 2021 DOI: http://dx.doi.org/10.1590/2179-10742021v20i41152

TABLE I. PHYSICAL DIMENSIONS OPTIMIZED FOR THE FILTER

\begin{tabular}{ccccc}
\hline $\begin{array}{c}\text { Filter } \\
\text { length }(\mathbf{m m})\end{array}$ & $\begin{array}{c}\text { Trapezoid } \\
\text { height }(\mathbf{m m})\end{array}$ & $\begin{array}{l}\mathbf{L}_{\mathbf{b}} \\
(\mathbf{m m})\end{array}$ & $\begin{array}{c}\text { Smaller } \\
\text { base }(\mathbf{m m})\end{array}$ & $\begin{array}{c}\mathbf{S} \\
(\mathbf{m m})\end{array}$ \\
\hline 30 & 6.25 & 24.7 & 2.2 & 1
\end{tabular}

The final values used in the equivalent circuit are shown in Table II and its $\left|\mathrm{S}_{11}\right|(\mathrm{dB})$ and $\left|\mathrm{S}_{21}\right|(\mathrm{dB})$ in Fig. 8.

TABLE II. OPTIMIZED VALUES FOR THE EQUIVALENT CIRCUIT

\begin{tabular}{ccccc}
\hline $\mathbf{C}_{\mathbf{p}}(\mathbf{p F})$ & $\mathbf{C}_{\mathbf{g}}(\mathbf{p F})$ & $\mathbf{C}_{\mathbf{T}}(\mathbf{p F})$ & $\mathbf{L}(\mathbf{n H})$ & $\mathbf{F}_{\mathbf{r}}(\mathbf{G H z})$ \\
\hline 3.06 & 0.031 & 4.09 & 3.21983 & 2.495
\end{tabular}

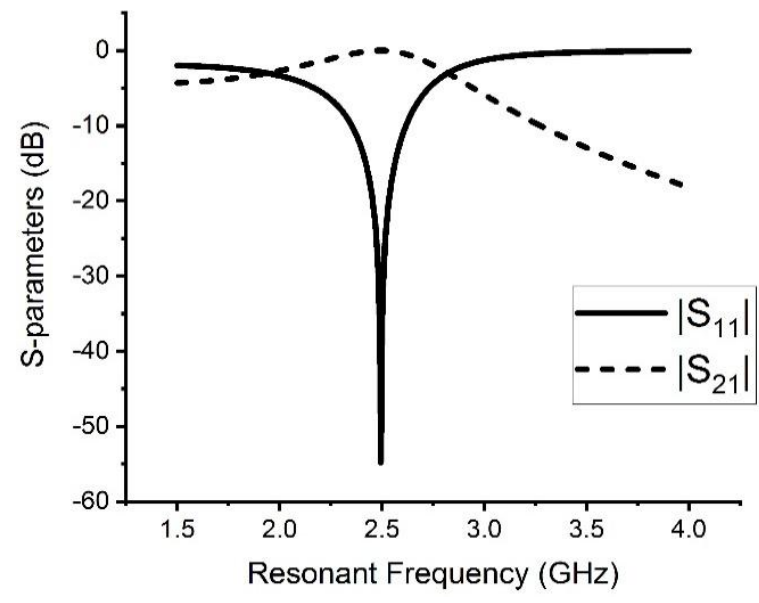

Fig. 8. S-Parameters for the optimized equivalent circuit.

As observed in the equivalent circuit in Fig. $4, C_{T}$ has a great influence on resonant frequency results. Some $C_{T}$ capacitance values were simulated for that circuit presented. Using the Table II values of $C_{p}, C_{g}$ and $L$, one obtains $f \cup s C_{t}$ results, as shown in Fig. 9. The function that represents this relation is approximately $f\left(C_{T}\right)=3.5237-0.25842 C_{T}$.

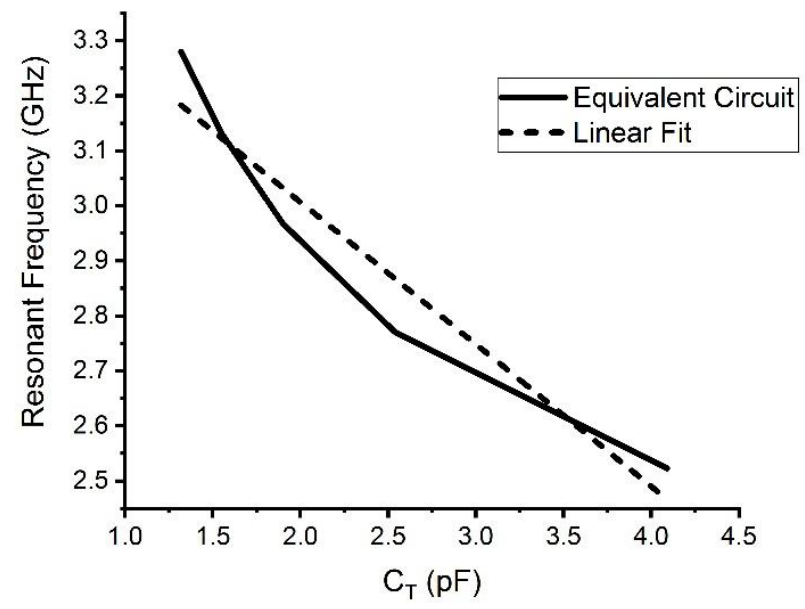

Fig. 9. Relationship between $\mathrm{Ct}$ and the resonant frequency. 


\section{Reconfigurable filtenna}

A filtenna is the integration of an antenna with an RF filter, which is normally inserted into the antenna feedline, ground plane [29] or on the antenna radiation element [30]. The advantage of integrating the filter on the antenna feed line is the ease of antenna frequency response reconfiguration without changing the radiant element and maintaining the desired base antenna parameters [31].

The UWB antenna and the trapezoidal filter described in section II in combination, form the proposed filtenna. The filter is placed on the antenna feedline and is used for operational frequency selection.

In this project, the reflection coefficient of the filtenna is $\leq-10 \mathrm{~dB}$ that represents that more than $90 \%$ of the fed power is absorbed [32]. This value is also used in MIMO "systems" [32] [33] and cognitive radio applications [34].

\section{EXPERIMENTAL DEMONSTRATION}

\section{A. UWB planar monopole antenna}

The type of antenna chosen is an UWB planar circular monopole because has desirable design features such as low cost, ease of design and fabrication.

The UWB monopole antenna features a compact structure and circular geometry, with a broadband frequency response. The substrate used is FR-4 with dielectric constant of $\varepsilon_{r}=4.3$ and substrate thickness of $1.6 \mathrm{~mm}$. The antenna is $80 \mathrm{~mm}$ wide and $100 \mathrm{~mm}$ long. The feedline has $50 \Omega$ impedance and $3 \mathrm{~mm}$ width, as shown in Fig. 10. The circular patch has a radius $R$ of $30 \mathrm{~mm}$, and the ground plane has an area of $80 \times 30 \mathrm{~mm}$. The antenna frequency of operation is defined from $1.5 \mathrm{GHz}$ to 4 $\mathrm{GHz}$.

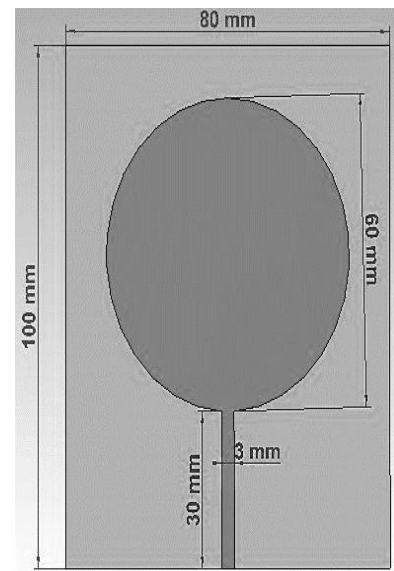

(a)

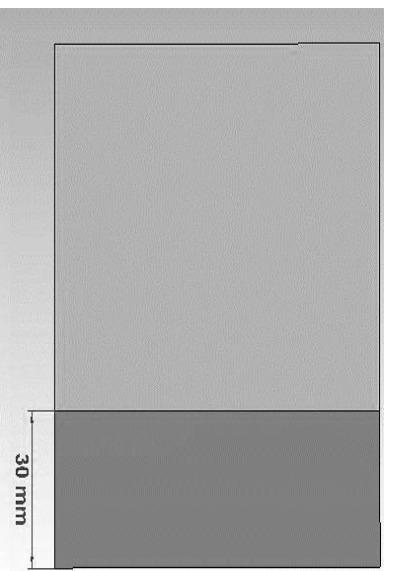

(b)

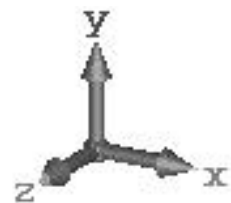

(c)

Fig. 10. UWB antenna dimensions: (a) Front view; (b) Rear view (ground plane); (c) Coordinate system.

The antenna was modeling in the CST Studio Suite ${ }^{\circledR}$ software and fabricated using the printed circuit prototyping machine EP2006H manufactured by EverPrecision ${ }^{\circledR}$. An FR-4 substrate with double side metal is used having the antenna geometry on one side and the ground plane on the other. 
Journal of Microwaves, Optoelectronics and Electromagnetic Applications, Vol. 20, No. 4, December 2021

DOI: http://dx.doi.org/10.1590/2179-10742021v20i41152

The SMA connector is soldered to the fabricated filtenna to perform measurements.

The antenna is connected to a vector network Analyzer, Agilent ${ }^{\circledR}$ E5071B through a precision cable with the objective of measuring filtenna magnitude of $S_{11}$. The result presented by the network analyzer corresponds to the magnitude of $S_{11}$ as a function of frequency, measured in relation to a 50 $\Omega$ impedance (input impedance of the network analyzer used). Fig. 11 shows the antenna measurement setup and Fig. 12 contains the simulated and measured magnitude of $\mathrm{S}_{11}$ confirming the UWB behavior of the antenna. All values of $\left|\mathrm{S}_{11}\right|$ in the band of operation, from 1.5 to $4 \mathrm{GHz}$ are below $-10 \mathrm{~dB}$.

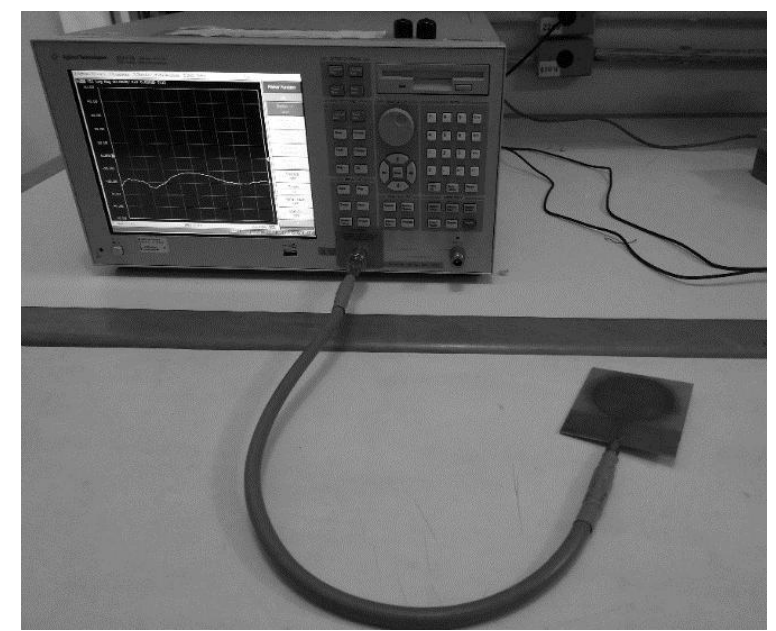

Fig. 11. Manufactured UWB antenna in the experimental setup.

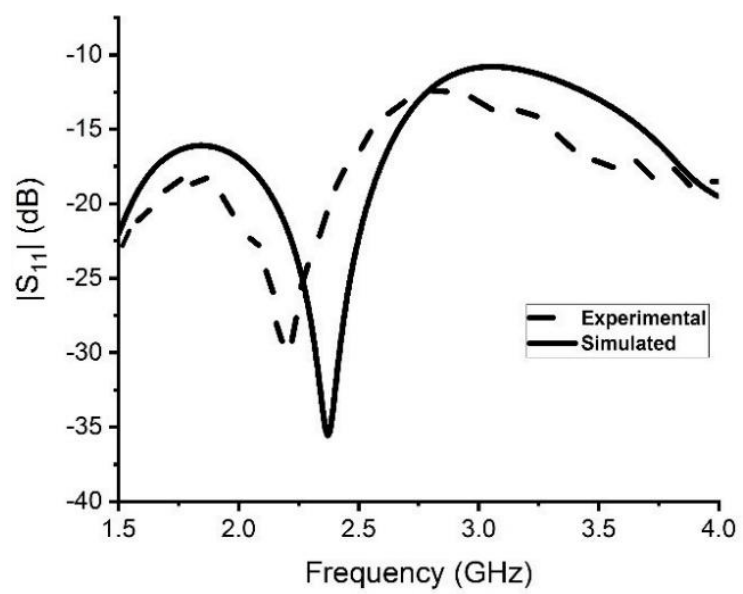

Fig. 12. Simulated and experimental magnitude of $\mathrm{S}_{11}$ of the UWB antenna.

Simulated and measured results are in good agreement, despite a frequency shift of approximately $120 \mathrm{MHz}$, this shift may be expected, since the measurement was not performed in a fully shielded environment, where the frequency of operation can be altered by the environment surrounding the antenna. Other reasons that may have led to this frequency shift are the milling manufacturing process tolerances, connector irregularities in both construction and mounting. The measurement is within a tolerable range, which is usually $10 \%$ of the $2.25 \mathrm{GHz}$ center frequency value. This range was used throughout the work as the frequency deviation limit. The UWB antenna has a broadband behavior, Brazilian Microwave and Optoelectronics Society-SBMO received 10 Dec 2020; for review 17 Dec 2020; accepted 6 Aug 2021 
Journal of Microwaves, Optoelectronics and Electromagnetic Applications, Vol. 20, No. 4, December 2021 DOI: http://dx.doi.org/10.1590/2179-10742021v20i41152

with radiation pattern for the operation frequencies almost unchanged and made with a low cost and relatively easy construction.

Fig. 13 shows the simulations of the total field on the principal planes for the normalized radiation pattern in elevation (plane Y-Z) and Fig. 14. shows the azimuth (plane X-Y) for the frequencies 2.2 $\mathrm{GHz}, 2.725 \mathrm{GHz}$ and $3.25 \mathrm{GHz}$. There is a slight variation of the radiation pattern diagram observed between the low and high frequency of operation.

Farfield Gain Abs (Phi=90)

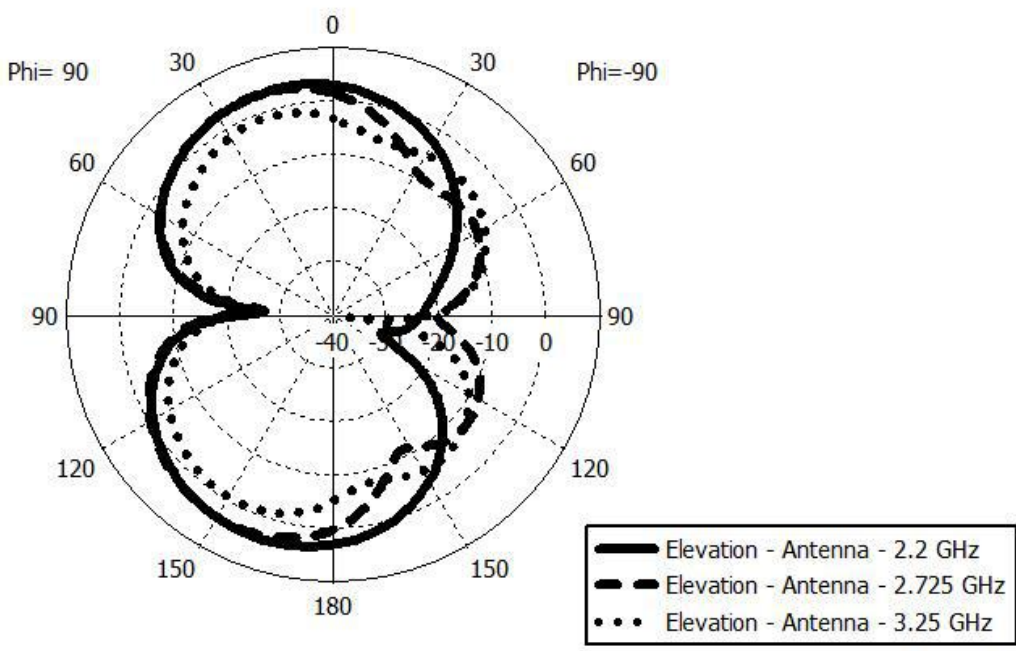

Theta / Degree vs. dB

Fig. 13. 2D elevation radiation pattern.

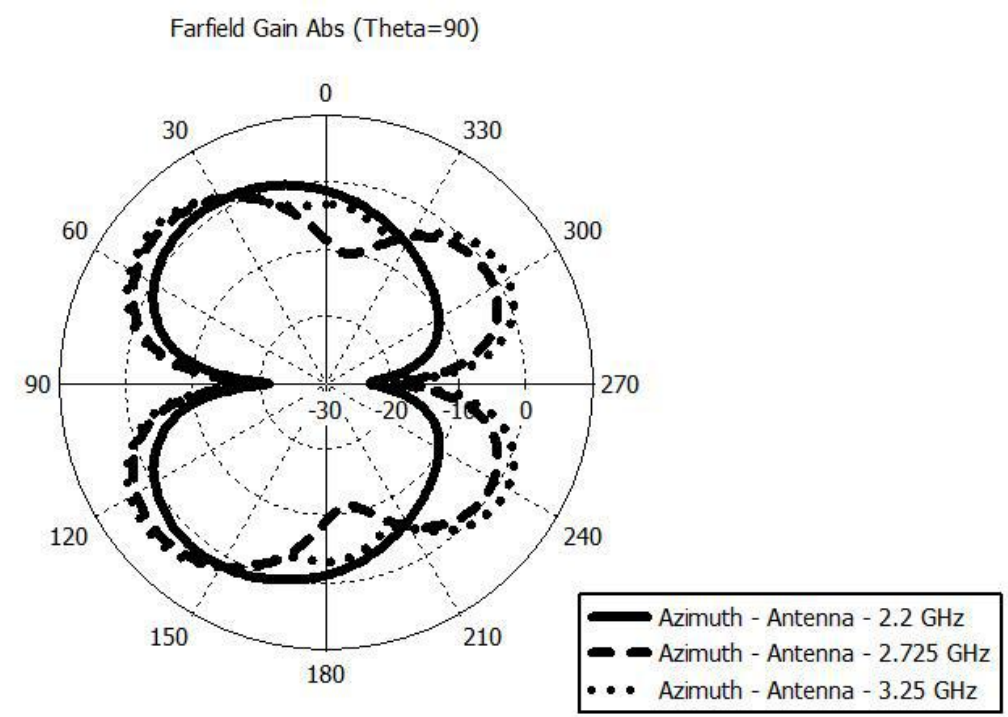

Phi / Degree vs. dB

Fig. 14. 2D azimuth radiation pattern. 


\section{B. Reconfigurable trapezoidal filter}

The antenna frequency of operation can be tuned by using a band-pass filter on its transmission line (feed). The filter chosen is a band-pass type, with trapezoidal resonator geometry, and has the dimensions shown in Fig. 15. The filter area is $30 \mathrm{~mm}$ x $30 \mathrm{~mm}$, designed using the same FR-4 substrate used to make the UWB antenna.

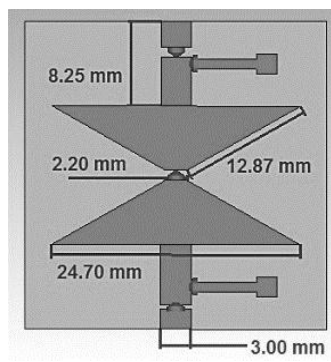

(a)

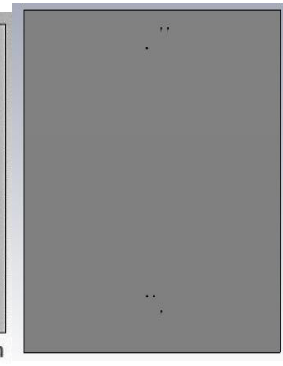

(b)

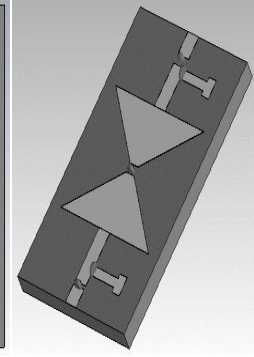

(c)

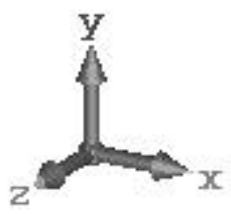

(d)

Fig. 15. Filter layout: (a) Front view; (b) Rear view; (c) 3D view; (d) Coordinate system.

The filter uses two metal tracks placed perpendicular to the structure to provide the DC bias voltage to the varactor diode, placed in the center of the structure. To prevent these DC bias tracks from influencing the RF response of the filter, two choke inductors are added. The model used in the simulation for the inductor was found in the manufacturer's datasheet. The simulation model used corresponds to a parallel RLC circuit with values of $\mathrm{R}=11.93 \mathrm{k} \Omega, \mathrm{L}=80.53 \mathrm{nH}$ and $\mathrm{C}=96.63 \mathrm{fF}$.

Other components used in the filter design are two DC blocks, namely $1 \mathrm{pF}$ capacitors, with broadband operation covering the operating frequencies of the filtenna, and do not interfere with the overall RF response. The DC blocks are placed on the transmission lines used to connect the filtenna to the network analyzer ports.

The capacitance values of the varactor " $\mathrm{C}_{\mathrm{T}}$ " are extracted from the manufacturer's datasheet. The varactor model is the SMV1234 from Skyworks ${ }^{\circledR}$, and has variable capacitance from $1.32 \mathrm{pF}$ to 9.63 $\mathrm{pF}$ when subjected to a reverse voltage " $V_{R}$ " from $0 \mathrm{~V}$ to $15 \mathrm{~V}$. The Varactor model used is accurate for reverse voltages ranging from $0 \mathrm{~V}$ to $15 \mathrm{~V}$, only values of $2.5 \mathrm{~V} ; 4.5 \mathrm{~V} ; 6.5 \mathrm{~V} ; 9 \mathrm{~V}$ and $15 \mathrm{~V}$ are considered, since it covers the desired frequency range of operation. According to the varactor datasheet, this model works over the entire $\mathrm{GHz}$ frequency designed for the system. In the simulation, a series RLC circuit with variable capacitance $\left(C_{T}\right)$ represented the varactor diode.

Table III relates the varactor capacitance values to reverse voltage values.

TABLE III. VARACTOR CAPACITANCE ACCORDING TO BIAS VOLTAGE

\begin{tabular}{cc}
\hline $\mathbf{V}_{\mathbf{R}}(\mathbf{V})$ & $\mathbf{C}_{\mathbf{T}}(\mathbf{p F})$ \\
\hline 2.5 & 4.09 \\
4.5 & 2.54 \\
6.5 & 1.90 \\
9.0 & 1.55 \\
15 & 1.32 \\
\hline
\end{tabular}


Journal of Microwaves, Optoelectronics and Electromagnetic Applications, Vol. 20, No. 4, December 2021 DOI: http://dx.doi.org/10.1590/2179-10742021v20i41152

After filter printed circuit board fabrication, discrete components are mounted, including two SMA connectors. Two $1 \mathrm{pF}$ DC block capacitors have been added to the filter transmission line to isolate the network Analyzer from the DC source. The reverse voltage is applied to the varactor through the DC bias lines that include a choke inductor that has the function of isolating the RF signal from the DC source.

Each SMA is connected to the network analyzer through flexible coaxial cables and the varactor bias is done using a benchtop DC power supply. A multimeter was also used to confirm the voltage value delivered to the device. The measurement setup is shown in Fig. 16.

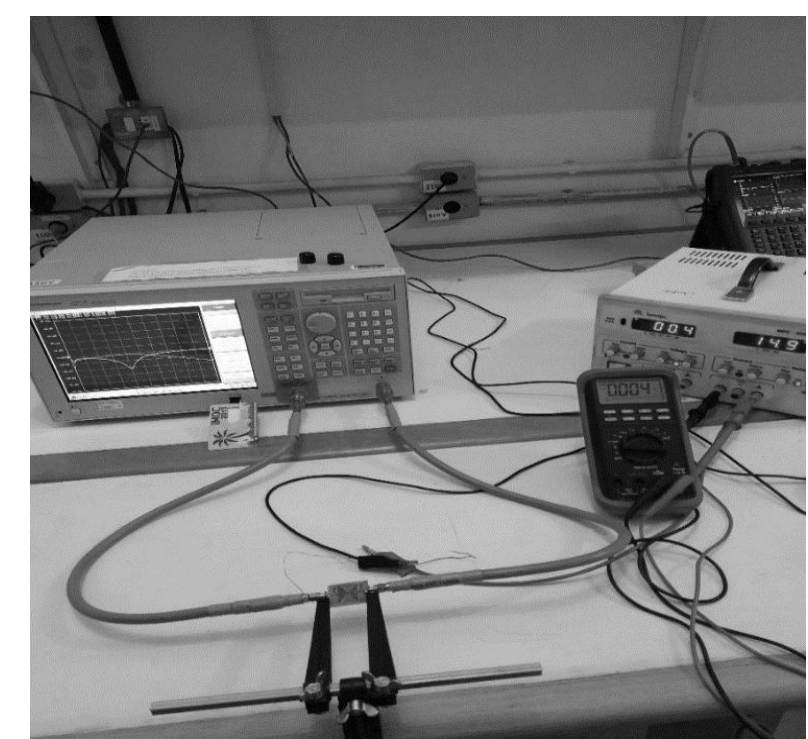

Fig. 16. Manufactured reconfigurable filter in the experimental setup.

The measurements used the same reverse voltage values, i.e., $2.5 \mathrm{~V} ; 4.5 \mathrm{~V} ; 6.5 \mathrm{~V} ; 9.0 \mathrm{~V}$ and $15.0 \mathrm{~V}$. Varactor polarization was performed according to the guidance of the datasheet. The $\left|\mathrm{S}_{11}\right|$ simulated response is shown in Fig. 17 and the $\left|\mathrm{S}_{21}\right|$ response in Fig. 18.

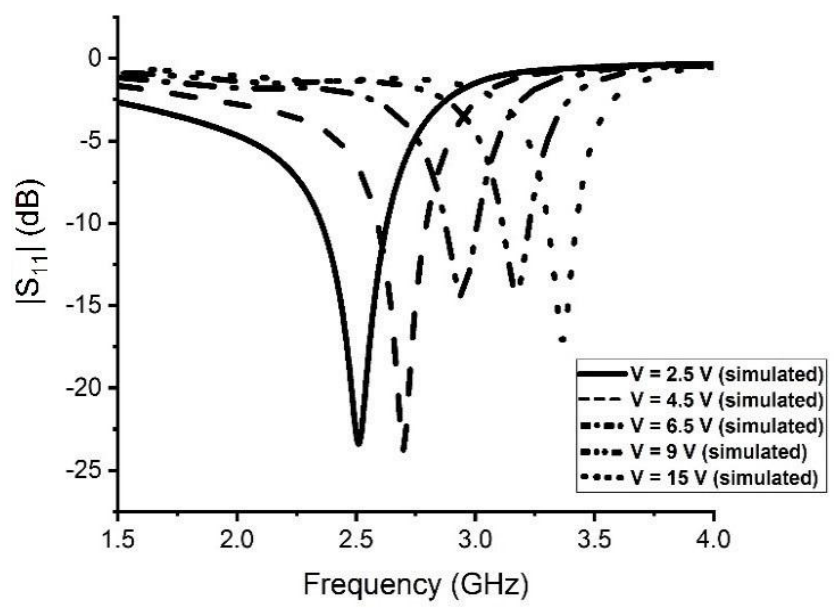

Fig. 17. Reconfigurable filter simulated $\left|\mathrm{S}_{11}\right|$. 


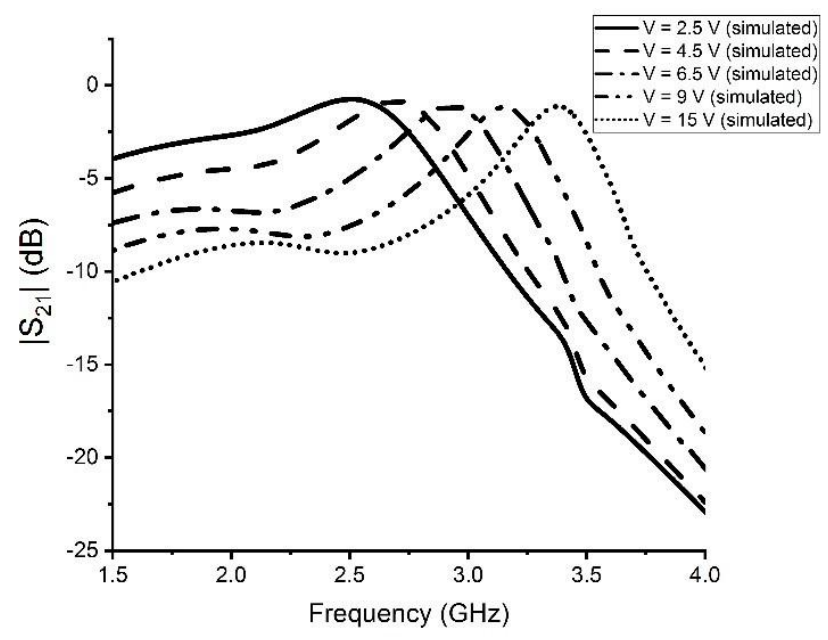

Fig. 18. Reconfigurable filter simulated $\left|\mathrm{S}_{21}\right|$.

Fig. 19 and Fig. 20 shows the experimental results according to varactor bias voltage and the figures Fig. 21 and Fig. 22 shows the simulation and experimental comparison for the lowest and highest frequency stage of the device, respectively.

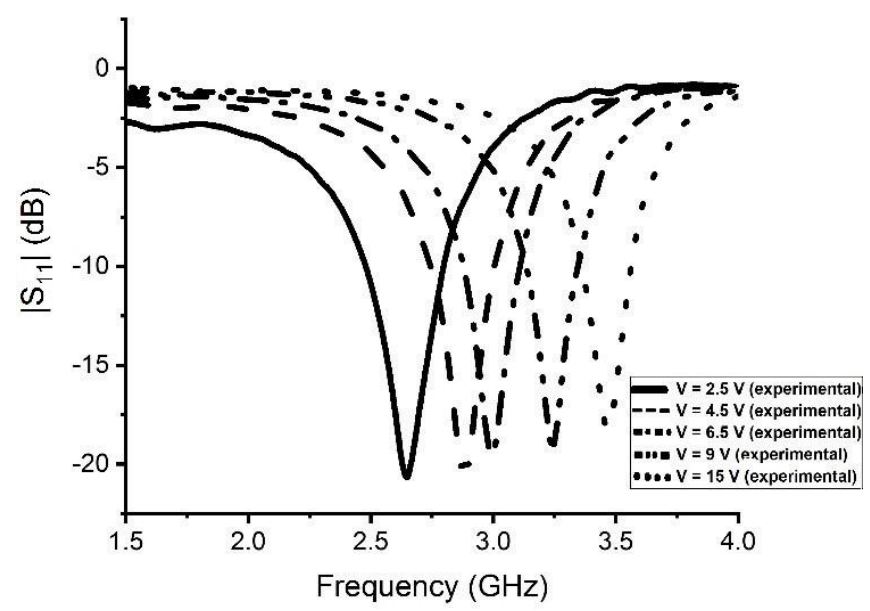

Fig. 19. Reconfigurable filter experimental $\left|\mathrm{S}_{11}\right|$ results.

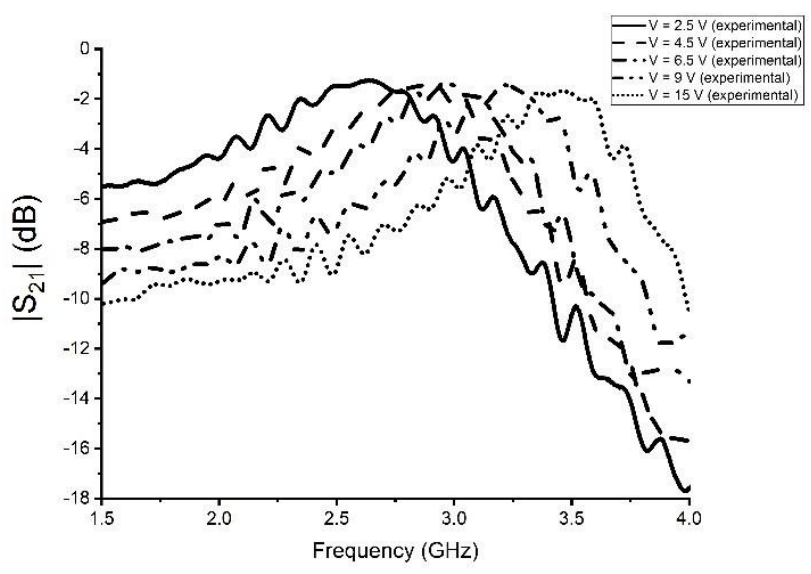

Fig. 20. Reconfigurable filter experimental $\left|S_{21}\right|$ results. 


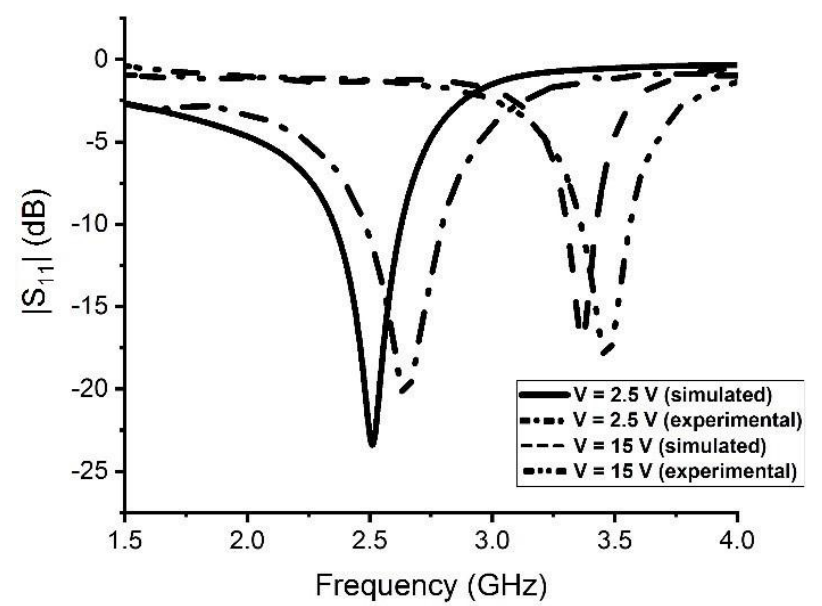

Fig. 21. Reconfigurable filter simulated vs experimental $\left|\mathrm{S}_{11}\right|$.

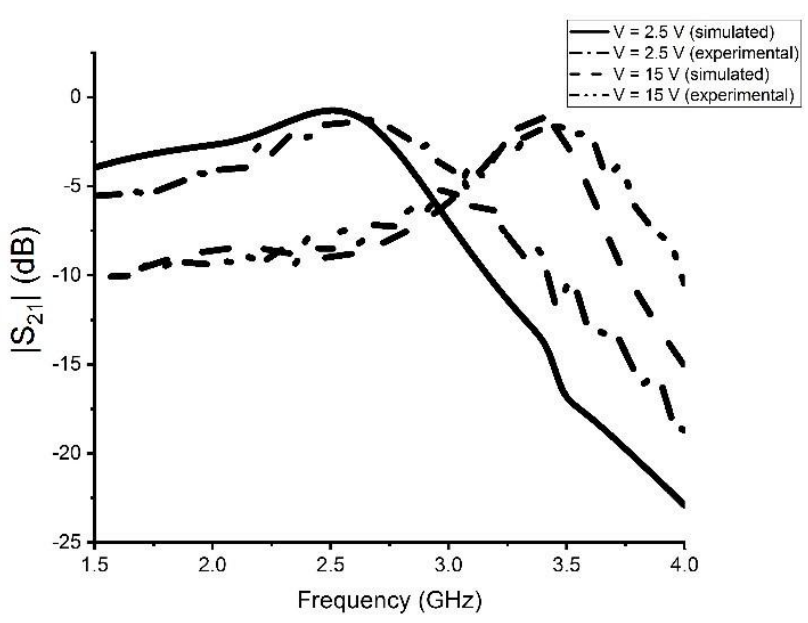

Fig. 22. Reconfigurable filter simulated vs experimental $\left|S_{21}\right|$.

It can be seen that an increase in applied reverse voltage results in an increase in operating frequency of the filter. The filter presented a band-pass behavior for the desired operating frequency range.

The filter operating frequency is reconfigurable according to the varactor diode capacitance variation. The prototype was modeled and checked through measurements and proved to be efficient and easily integrated in the final filtenna device.

\section{Reconfigurable filtenna}

The filtenna in Fig. 23 integrates the UWB antenna and filter, described in section III. One DC block capacitor is used, since the filtenna has only one SMA connector. The filtenna feed has an input impedance of $50 \Omega$. 


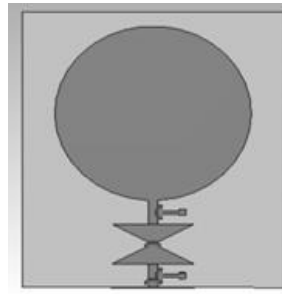

(a)

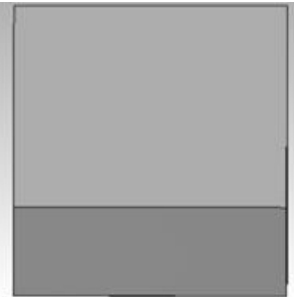

(b)

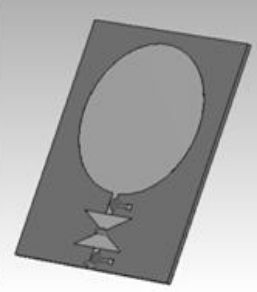

(c)

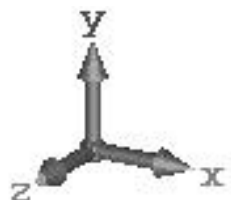

(d)

Fig. 23. Proposed filtenna: (a) Front view; (b) Rear view; (c) 3D view; (d) Coordinate system.

The filtenna has a tunable operating frequency due to the band-pass filter on its feed line. Varactor bias voltage is used to tune the operation frequency of the filtenna.

The filtenna is connected to a network analyzer port and varactor DC bias is supplied via a benchtop DC power supply. The network analyzer is calibrated with a manufacturer's calibration kit for each measurement performed.

The measured filtenna magnitude of $S_{11}$ is in the range from 1.5 to $4 \mathrm{GHz}$, in good agreement with simulations. The objective is to obtain an $\left|\mathrm{S}_{11}\right|$ below $-10 \mathrm{~dB}$, over the band of operation, including the five center frequencies of interest covering the frequency range from 1.5 to $4 \mathrm{GHz}$.

Fig. 24 shows the experimental setup used to measure the filtenna reconfigurable magnitude of $S_{11}$. Fig. 25 shows the simulated magnitude of $S_{11}$, Fig. 26 shows the filtenna experimental magnitude of $\mathrm{S}_{11}$, and Fig. 27. shows the comparison between simulated and measured results for the lowest and highest filtenna frequency of operation.

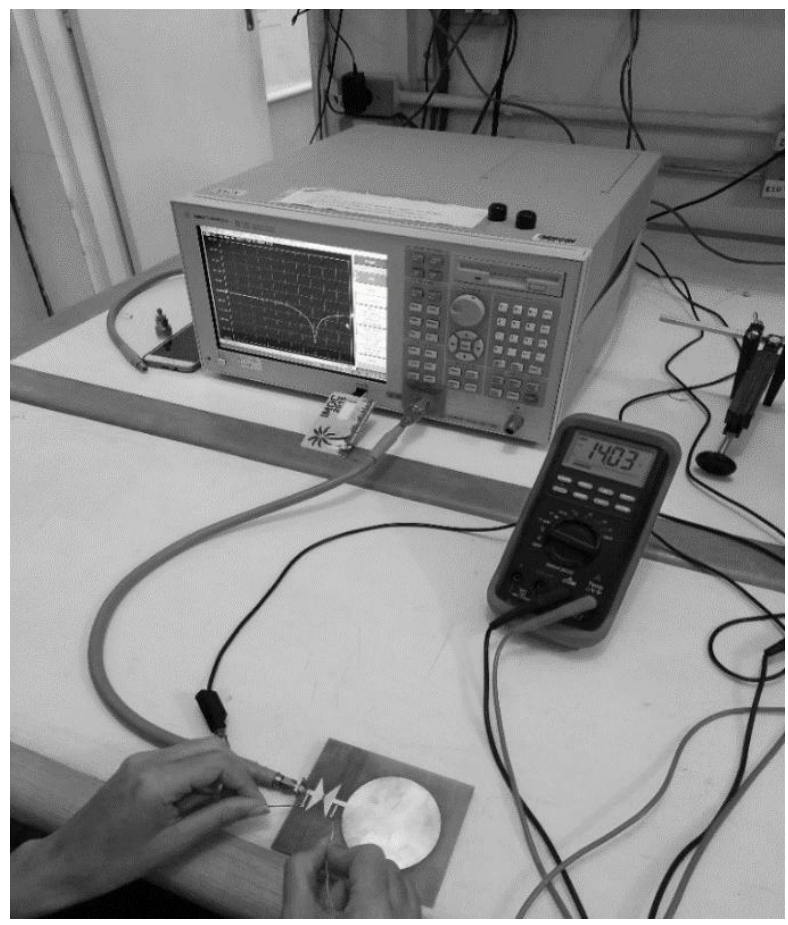

Fig. 24. Manufactured reconfigurable filtenna in the experimental setup. 


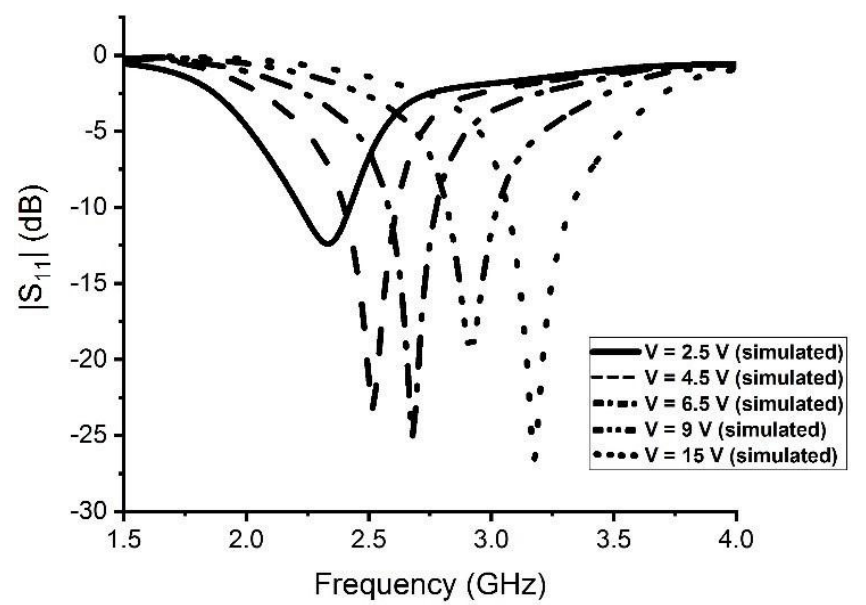

Fig. 25. Reconfigurable filtenna simulated magnitude of $\mathrm{S}_{11}$.

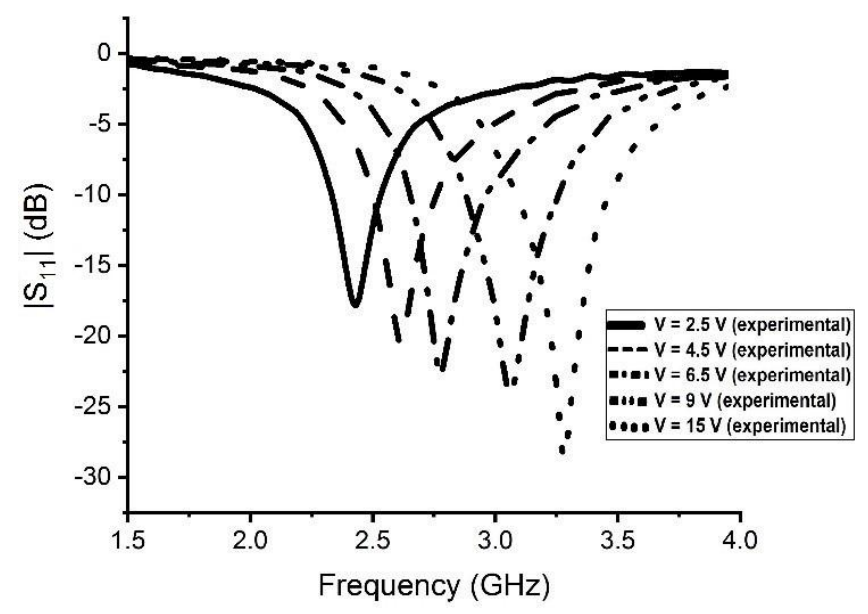

Fig. 26. Reconfigurable filtenna experimental magnitude of $\mathrm{S}_{11}$.

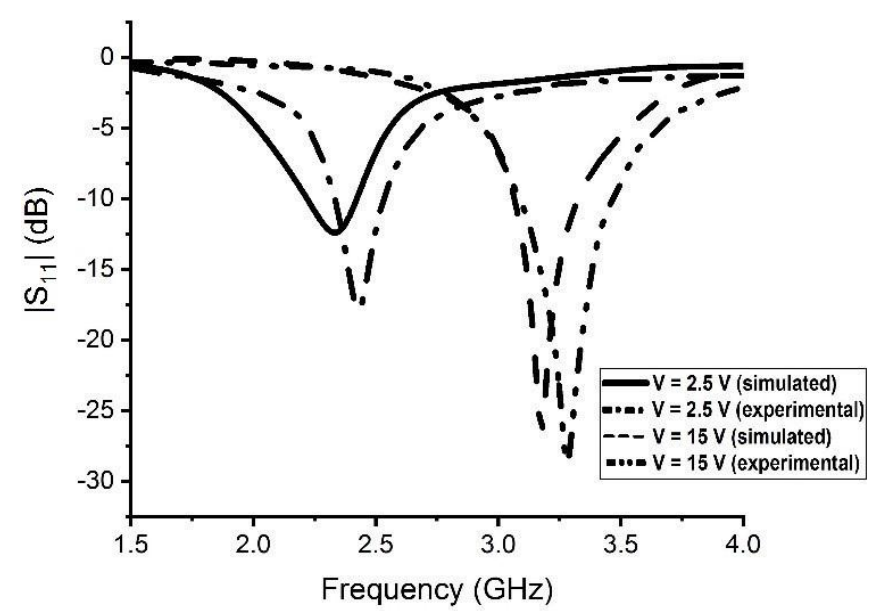

Fig. 27. Reconfigurable filtenna simulated vs experimental magnitude of $S_{11}$.

The proposed filtenna operates with $\left|\mathrm{S}_{11}\right|$ below $-10 \mathrm{~dB}$, achieved in simulations in the frequency range from $2.2 \mathrm{GHz}$ to $3.25 \mathrm{GHz}$ when the reverse voltage applied in the varactor varies from $2.5 \mathrm{~V}$ to $15 \mathrm{~V}$. For threshold of $-10 \mathrm{~dB}$, one observes voltages and the following correspondent frequency ranges: $2.5 \mathrm{~V}$ for $2.2-2.4 \mathrm{GHz}, 4.5 \mathrm{~V}$ for $2.4-2.65 \mathrm{GHz}, 6.5 \mathrm{~V}$ for $2.55-2.75 \mathrm{GHz}, 9 \mathrm{~V}$ for $2.75-3$ $\mathrm{GHz}$ and $15 \mathrm{~V}$ for $3-3.25 \mathrm{GHz}$. 
Journal of Microwaves, Optoelectronics and Electromagnetic Applications, Vol. 20, No. 4, December 2021 DOI: http://dx.doi.org/10.1590/2179-10742021v20i41152

In measurements, the range is from $2.3 \mathrm{GHz}$ to $3.4 \mathrm{GHz}$, where a $100 \mathrm{MHz}$ offset is found between simulations and measurements.

Increasing the applied reverse bias voltage to the varactor diode, results in an increase in operating frequency of the filtenna.

The idea of being able to reconfigure the operating frequency of an antenna without changing its main parameters is one of the main advantages of using the filtenna, verified by comparing the radiation pattern for each reverse voltage applied to the filtenna.

Fig. 28 and Fig. 29 show the filtenna radiation pattern at $2.2 \mathrm{GHz}, 2.725 \mathrm{GHz}$ and $3.25 \mathrm{GHz}$. The patterns were simulated for the filter at $15 \mathrm{~V}$ of applied reverse voltage, but when other voltage values were considered, the patterns remained the same.

Farfield Gain Abs (Phi=90)

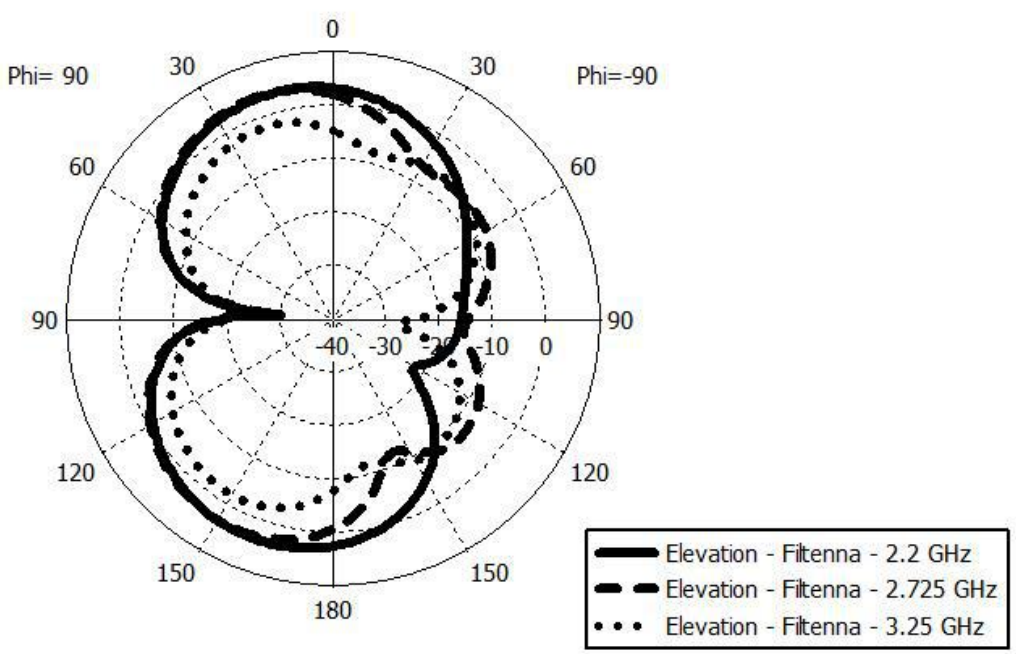

Theta / Degree vs. dB

Fig. 28. 2D elevation radiation pattern.

Farfield Gain Abs (Theta $=90$ )

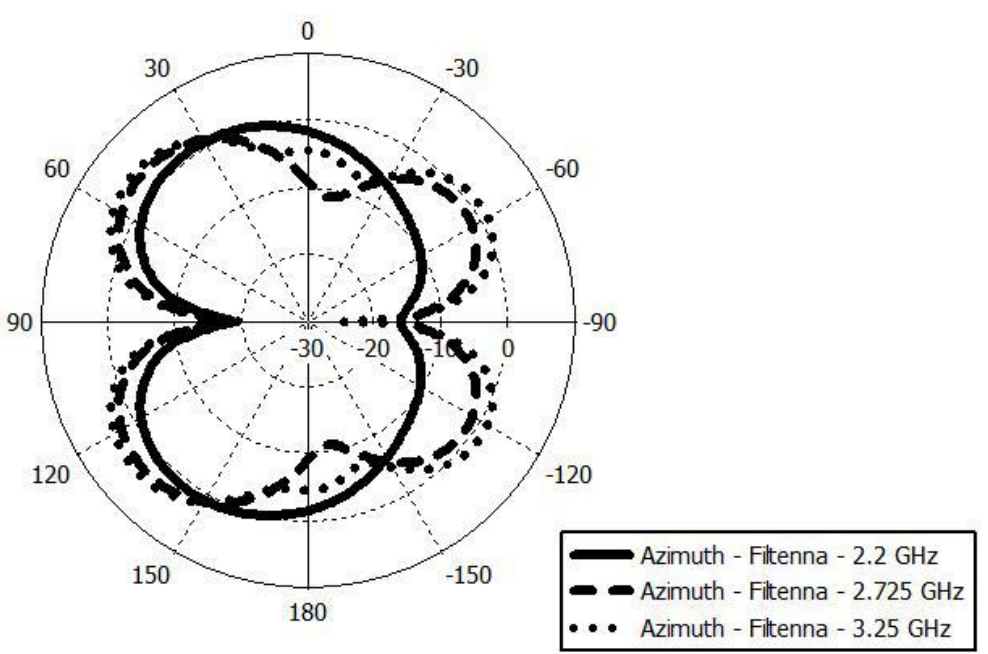

Phi / Degree vs. dB

Fig. 29. 2D azimuth radiation pattern. 
Journal of Microwaves, Optoelectronics and Electromagnetic Applications, Vol. 20, No. 4, December 2021 DOI: http://dx.doi.org/10.1590/2179-10742021v20i41152

The figures 30, 31 and 32 correspond to the comparison of the diagrams for the antenna (system without filter) and for the filtenna (system with filter) in the frequencies of $2.2 \mathrm{GHz}, 2.725 \mathrm{GHz}$ and $3.25 \mathrm{GHz}$. It is possible to notice that the filter is able to add the reconfiguration capacity to the monopole antenna presented without practically degrade the antenna gain. .

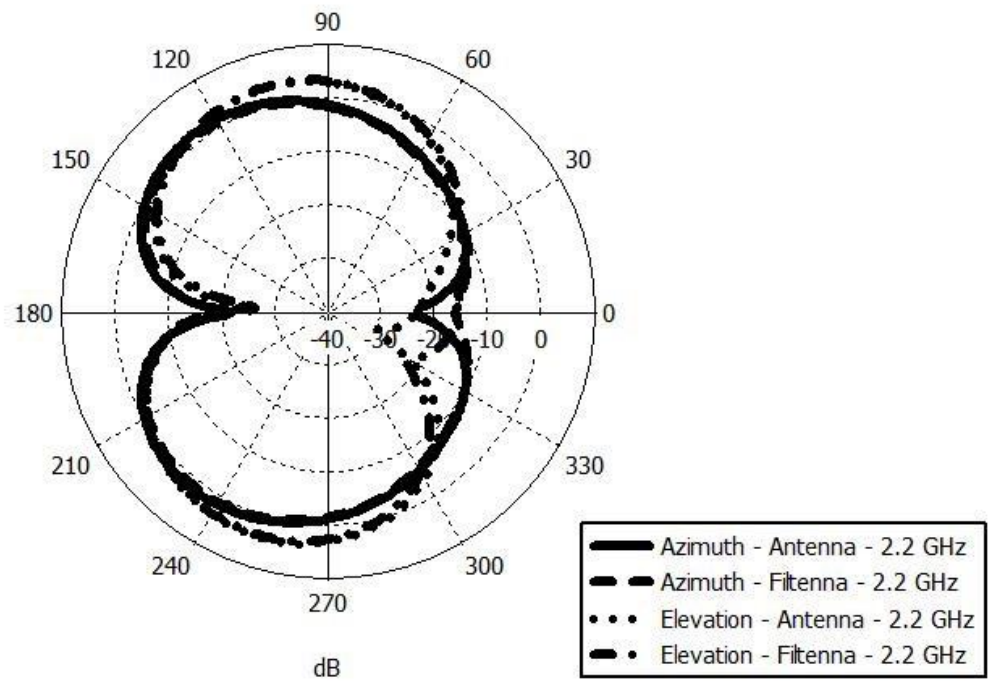

Fig. 30. 2D radiation pattern for antenna and filtenna at $2.2 \mathrm{GHz}$.

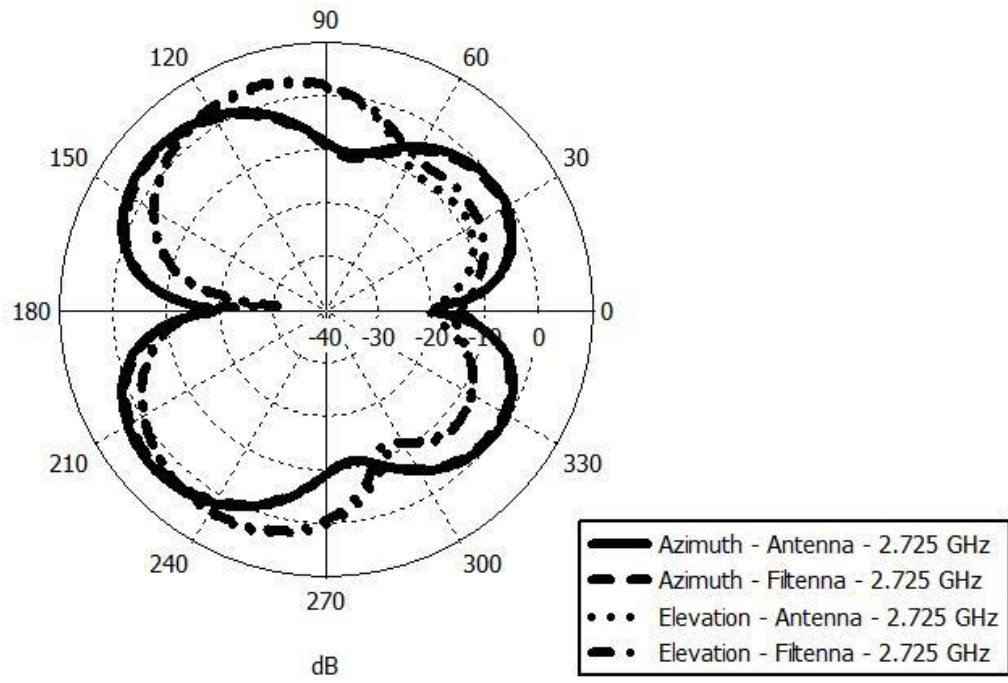

Fig. 31. 2D radiation pattern for antenna and filtenna at $2.725 \mathrm{GHz}$. 


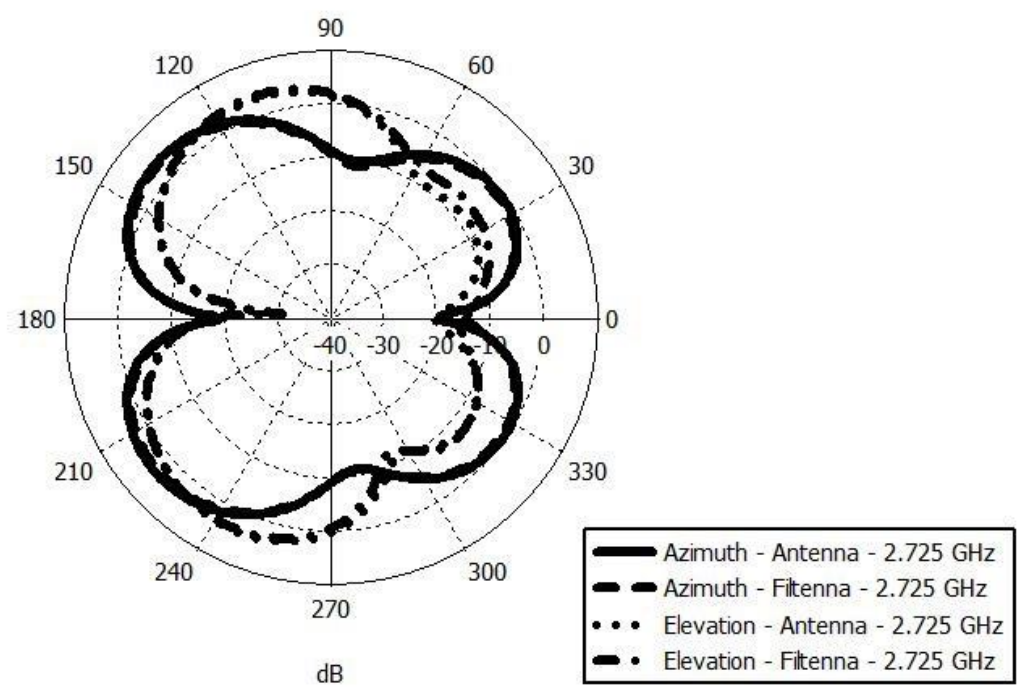

Fig. 32. 2D radiation pattern for antenna and filtenna at $3.25 \mathrm{GHz}$.

\section{CONCLUSION}

This manuscript presents a device known as filtenna that consists of the association between a circular planar monopole antenna with a trapezoidal geometry filter capable of reconfiguring its operating frequency. The device was validated through simulations and measurements. According to what has been presented, adding a reconfigurable band-pass filter to a ultrawide antenna is suitable for several applications. In addition to the selectivity and ability of been reconfigurable, the insertion of the filter in the feed line does not disturb device electromagnetic properties.

The proposed filter has trapezoidal geometry and presents its frequency response reconfigurable due to a varactor diode present in its structure. The capacitance $(\mathrm{Ct})$ of the varactor diode is a function of the applied reverse voltage. The filter was designed according to its equivalent circuit where it was possible to analyze and relate its physical dimensions to the frequency response as well as the influence of the varactor diode on its operation. According to the $-10 \mathrm{~dB}$ threshold, the multiband system operates in the bands of $2.3-2.65 \mathrm{GHz}, 2.5-2.8 \mathrm{GHz}, 2.7-3 \mathrm{GHz}, 3-3.25 \mathrm{GHz}$ and $3.25-$ $3.45 \mathrm{GHz}$, for applied voltage values of $2.5,4.5,6.5,9$ and $15 \mathrm{~V}$, respectively.

It is possible to affirm based on both datasheet and the chosen equivalent circuit model if the applied reverse voltage increases, the varactor capacitance $\left(\mathrm{C}_{\mathrm{t}}\right)$ decreases and in turn, the operating frequency increases.

The proposed filtenna, in turn, with the threshold of $-10 \mathrm{~dB}$ operates in the bands of $2.2-2.4 \mathrm{GHz}$, $2.4-2.65 \mathrm{GHz}, 2.55-2.75 \mathrm{GHz}, 2.75-3 \mathrm{GHz}$ and $3-3.25 \mathrm{GHz}$, for applied reverse voltage values $2.5,4.5,6.5,9$ and $15 \mathrm{~V}$, respectively. The filtenna has its operating frequency reconfigurable with the variation of the applied reverse voltage. 
Journal of Microwaves, Optoelectronics and Electromagnetic Applications, Vol. 20, No. 4, December 2021 DOI: http://dx.doi.org/10.1590/2179-10742021v20i41152

The idea of being able to reconfigure the operating frequency of an antenna without changing its main parameters is one of the main advantages of inserting a filter on the antenna feed line. This can be verified by comparing the radiation pattern for the antenna with and without the filter, as present in the Fig. 30, 31 and 32.

Due to its low cost characteristics, ease of manufacture and reconfiguration capacity, this filtenna can be minimally adjusted to work in wireless systems such as Wi-Fi, MIMO and radio cognitive systems.

\section{ACKNOWLEDGMENT}

This work was financed by the Brazilian agencies, CAPES and CNPq. This work is supported by the Spanish government under MICINN grant RTI2018-099841-B-I00. Part of this work has been supported by the Generalitat de Catalunya under grant 2017 SGR 891.

\section{REFERENCES}

[1] M. Chung and C. Yang, "Built-in antenna design for $2.4 \mathrm{GHz}$ ISM band and GPS operations in a wrist-worn wireless communication device", IET Microwaves, Antennas \& Propagation, vol. 10, no. 12, pp. 1285-1291, 2016.

[2] N. Vikram, "Design of ISM band RFID reader antenna for IoT applications", in Int. Conf. on Wireless Communications, Signal Processing and Networking, Chennai, 2016, pp. 1818-1821.

[3] M. Lazarescu, "Design of a WSN Platform for Long-Term Environmental Monitoring for IoT Applications", IEEE Journal on Emerging and Selected Topics in Circuits and Systems, vol. 3, no. 1, pp. 45-54, 2013.

[4] B. Andrade, "Estudo de arranjos de antenas de microfita com Patch quase-fractal para comunicações sem fio", M.Sc., Universidade Federal do Rio Grande do Norte, 2014.

[5] Wei-Jun Wu, Ying-Zeng Yin, Shao-Li Zuo, Zhi-Ya Zhang and Jiao-Jiao Xie, "A New Compact Filter-Antenna for Modern Wireless Communication Systems", IEEE Antennas and Wireless Propagation Letters, vol. 10, pp. 1131-1134, 2011. [6] G. Goussetis and D. Budimir, "Antenna filter for modern wireless systems", in 32nd European Microwave Conference, Milan, 2002, pp. 1-3.

[7] O. Nova, J. Bohorquez, N. Pena, G. Bridges, L. Shafai and C. Shafai, "Filter-Antenna Module Using Substrate Integrated Waveguide Cavities", IEEE Antennas and Wireless Propagation Letters, vol. 10, pp. 59-62, 2011.

[8] Jianhong Zuo, Xinwei Chen, Guorui Han, Li Li and Wenmei Zhang, "An Integrated Approach to RF Antenna-Filter CoDesign", IEEE Antennas and Wireless Propagation Letters, vol. 8, pp. 141-144, 2009.

[9] M. Al-Husseini, A. Ramadan, M. Zamudio, C. Christodoulou, A. El-Hajj and K. Kabalan, "A UWB antenna combined with a reconfigurable bandpass filter for cognitive radio applications", in IEEE-APS Topical Conference on Antennas and Propagation in Wireless Communications, Torino, 2011, pp. 902-904.

[10] M. Zamudio, Y. Tawk, J. Costantine, J. Kim and C. Christodoulou, "Integrated cognitive radio antenna using reconfigurable band pass filters", in 5th European Conference on Antennas and Propagation, Rome, 2011, pp. $2108-2112$ [11] W. Ahmad and D. Budimir, "Reconfigurable UWB filtennas with sharp WLAN dual bandnotch", in 45nd European Microwave Conference, Paris, 2015, pp. 1228-1231.

[12] J. A. Araujo, M. Oliveira, P. Cavalcanti, W. Felix, F. Lucena and M. T. de Melo, "Filtena Reconfigurável usando Diodo Varactor para Aplicações em Sistemas IoT", in 2018 MOMAG, Santa Rita do Sapucaí, 2018.

[13] D. González, "Estudio comparativo del estandar ultrawideband frente a bluetooth y zigbee", M.Sc., Universidad Austral de Chile, 2011.

[14] M. Ghavami, L. Michael and R. Kohno, Ultra wideband signals and systems in communication engineering. John Wiley \& Sons, 2007.

[15] C. Guerra, "Diseño antena textil para aplicaciones de alto riesgo", M.Sc., Pontificia Universidad Catolica de Valparaiso, 2017.

[16] Y. Li, W. Li and Q. Ye, "A Reconfigurable Triple-Notch-Band Antenna Integrated with Defected Microstrip Structure Band-Stop Filter for Ultra-Wideband Cognitive Radio Applications", International Journal of Antennas and Propagation, vol. 2013, pp. 1-13, 2013.

[17] X. Chen, F. Zhao, L. Yan and W. Zhang, "A Compact Filtering Antenna With Flat Gain Response Within the Passband", IEEE Antennas and Wireless Propagation Letters, vol. 12, pp. 857-860, 2013.

[18] J. Liang, C. Chiau, X. Chen and C. Parini, "Printed circular disc monopole antenna for ultra-wideband applications", Electronics Letters, vol. 40, no. 20, pp. 1246-1247, 2004.

[19] G. Bozdag and A. Kustepeli, "Wideband planar monopole antennas for GPS/WLAN/WiMAX/UWB and X-band applications", Microwave and Optical Technology Letters, vol. 58, no. 2, pp. 257-261, 2015.

[20] X. Chen, L. Guo, J. Liang and C. Parini, "On the performance of UWB monopole antennas", in IEEE Int. Conf. on Ultra-Wideband, Singapore, 2007, pp. 210-213.

[21] G. Kumar and K. Ray, Broadband microstrip antennas. Boston: Artech House, 2003. 
Journal of Microwaves, Optoelectronics and Electromagnetic Applications, Vol. 20, No. 4, December 2021

DOI: http://dx.doi.org/10.1590/2179-10742021v20i41152

[22] S. Mishra, R. Gupta and J. Mukherjee, "Parallel metal-plated tuning fork shaped omnidirectional monopole antenna for UWB application", Microwave and Optical Technology Letters, vol. 53, no. 3, pp. 601-604, 2011.

[23] S. Zito, "Projeto e Análise de Etiquetas RFID Chipless com Multiressonador", M.Sc., Universidade Federal de Minas Gerais, 2018.

[24] F. Ferreira and M. Heckler, "Filtro passa-faixa em tecnologia de microfita", in 11nd Salão Internacional de Ensino, Pesquisa e Extensão, Curitiba, 2014.

[25] B. Doken and M. Kartal, "Frequency selective surface with wide range of tunability," in 2017 Conference on Microwave Techniques (COMITE), Brno, Czech Republic, 2017, pp. 1-4.

[26] J. Hong, Microstrip filters for RF/microwave applications, 2nd ed. Hoboken, N.J.: Wiley, 2011.

[27] Jang-Sik Yoon et al., "A new DGS resonator and its application to bandpass filter design," in 2004 IEEE MTT-S International Microwave Symposium Digest, Fort Worth, TX, USA, 2004, pp. 1605-1608.

[28] A. Munir, B. D. Wulandari, W. Aditomo and Y. Prasetio, "DGS-based UWB microstrip bandpass filter and its equivalent circuit," in 2017 IEEE 13th Malaysia International Conference on Communications (MICC), Johor Bahru, Malaysia, 2017, pp. 70-73.

[29] Y. Tawk, J. Costantine, K. Avery and C. Christodoulou, "Implementation of a Cognitive Radio Front-End Using Rotatable Controlled Reconfigurable Antennas", IEEE Transactions on Antennas and Propagation, vol. 59, no. 5, pp. 17731778,2011

[30] X. Artiga, J. Perruisseau-Carrier, P. Pardo-Carrera, I. Llamas-Garro and Z. Brito-Brito, "Halved Vivaldi Antenna With Reconfigurable Band Rejection", IEEE Antennas and Wireless Propagation Letters, vol. 10, pp. 56-58, 2011.

[31] L. Silva, A. Alves and A. Cerqueira Sodré, "Optically Controlled Reconfigurable Filtenna", International Journal of Antennas and Propagation, vol. 2016, pp. 1-9, 2016.

[32] M.K. Mohsen, M.S. Isa, T.A. Rahman, M.K. Abdulhameed, A.A. Isa, M.S. Zin, S. Saat, Z. Zakaria, I.M. Ibrahim, M. Abu, A. Ahmad, "Novel Design and Implementation of MIMO Antenna for LTE Application", Journal of Telecommunication, Electronic and Computer Engineering (JTEC), 10(2), pp. 43-49, 2018.

[33] N. O. Parchin, H. J. Basherlou, Y. Al-Yasir, A. Ullah, R. Abd-Alhameed and J. Noras, "Multi-Band MIMO Antenna Design with User-Impact Investigation for 4G and 5G Mobile Terminals", Sensors, vol. 19, no. 3, p. 456, 2019.

[34] A. Ramadan, J. Costantine, M. Al-Husseini, K. Kabalan, Y. Tawk and C. Christodoulou, "Tunable Filter-Antennas For Cognitive Radio Applications", Progress In Electromagnetics Research B, vol. 57, pp. 253-265, 2014. 